\title{
Tumor Cell Death via Apoptosis and Improvement of Activated Lymphocyte Cytokine Secretion by Extracts from Euphorbia Hebecarpa and Euphorbia Petiolata
}

\author{
Zahra Amirghofran ${ }^{1,2}$, Narjes Shekofteh ${ }^{1}$, Mehri Ghafourian ${ }^{3,4 *}$, Neda Khosravi ${ }^{3}$, \\ Kurosh Kalantar $^{1}$, Saeed Malek-Hosseini ${ }^{1}$
}

\begin{abstract}
Background: Immunomodulatory materials from natural herbs and the characterization of their immune enhancement effects may have tremendous potential as cancer treatment. The aim of the present study was to investigate the apoptosis-inducing activities of Euphorbia hebecarpa Boiss and Euphorbia petiolata Banks \& Sol. plant extracts and their effects on cytokine secretion by lymphocytes. Materials and Methods: We assessed the apoptosis-inducing effect of the plants' hexane extracts on previously determined sensitive cell lines (HeLa for E. hebecarpa and K562 for E. petiolata) by flow cytometry and measurement of caspase 3 activation. The apoptosis-related gene expressions were examined by real-time PCR. The effects of the extracts on lymphocyte proliferation and cytokine secretion were examined. Results: Flow cytometry analysis showed that the inhibitory effect of the extracts on tumor cell growth was due to cell apoptosis. The plant extracts at the $100 \mu \mathrm{g} / \mathrm{ml}$ dose induced apoptosis in HeLa $(98.5 \pm 0.1 \%)$ and $\mathrm{K} 562$ $(57.7 \pm 1.9 \%)$ cells. The extracts increased caspase 3 activation $(\approx 2$-fold $>$ control $)$. Real-time PCR showed Fas and Bax gene upregulation and Bcl-2 downregulation, which resulted in an increased Bax/Bcl-2 expression ratio. The extracts increased lymphocyte proliferation and increased levels of IFN- $\gamma$ production in the presence and absence of mitogen $(\mathrm{p}<0.05)$. They significantly increased IL-4 and decreased IL-10 secretion by mitogen-stimulated lymphocytes. E. hebecarpa also increased IL-17 release. Conclusion: These results have shown that both extracts possess antitumor activity by inducing apoptosis, possibly through both intrinsic and extrinsic pathways. In addition, they induced secretion of different $\mathrm{T}$ helper subset related cytokines that are effective in the immune response against cancer.
\end{abstract}

Keywords: Euphorbia hebacarpa-Euphorbia petioleta- antitumor activity- cytokine

Asian Pac J Cancer Prev, 20 (7), 1979-1988

\section{Introduction}

Plants are a main source of highly effective conventional drugs for the treatment of many forms of cancer. Although the real compounds isolated from plants frequently may not be used as drugs, they lead the way for the development of potential novel agents (Cragg and Newman, 2005). Catharanthus roseus (L.) G. Don (Madagascar periwinkle, Apocynaceae) is a source of the vinca alkaloids vinblastine and vincristine. Isolation of these alkaloids is a valuable development in the use of plant substances as anticancer agents (Qu et al., 2015). Taxus brevifolia Nutt. (Taxaceae) and Camptotheca acuminata Decne (Nyssaceae), the sources of paclitaxel (Taxol) and etoposide, a semi-synthetic derivative of the natural products epipodophyllotoxin and camptothecin, are other examples that provide additional evidence for the promising use of natural products as medications and the importance of medicinal plants in anticancer treatment (Orlikova et al., 2014). The medicinal plant-derived agents are widely used as cancer treatments and account for a significant percentage of anticancer drugs in the market. Numerous other plants are being studied as potential cancer treatments.

Apoptosis is a main mechanism induced by anticancer agents. This process was originally described as a mechanism of controlled or physiological cell death and characterized by a variety of cellular changes from loss of membrane lipid asymmetry to DNA cleavage (Amirghofran et al., 2007). Apoptosis induction occurs via two pathways, extrinsic and intrinsic, resulting in caspase 3 activation. This key process is required for the execution of apoptosis (Tian et al., 2013).

The great majority of chemicals identified as cytotoxic

${ }^{1}$ Department of Immunology, ${ }^{2}$ Autoimmune Diseases Research Center, and Medicinal and Natural Products Chemistry Research Center, Shiraz University of Medical Sciences, Shiraz, ${ }^{3}$ Department of Immunology, Faculty of Medicine, ${ }^{4}$ Infectious and Tropical Diseases Research Center, Health Research Institute, Ahvaz Jundishapur University of Medical Sciences, Ahvaz, Iran. *For Correspondence: ghafourianbm@gmail.com 
to cancer cells are generally also toxic to normal cells. The potentiation of host defense mechanisms has been recognized as a possible means of inhibiting tumor growth without harming the host (Lissoni et al., 2008). Therefore, the search for immunomodulatory materials from natural herbs and characterization of their immune enhancement effects may have great potential in cancer treatment.

In recent years, researchers have identified a number of medicinal plants that have immunomodulating and antitumor activities. Examples include Aloe plants that have shown anticancer activities in vitro and in vivo (Harlev et al., 2012). The anti-neoplastic feature of these plants is attributed to at least three distinct mechanisms based on antiproliferative, immunostimulatory, and antioxidant effects (Harlev et al., 2012). Centella asiatica (L.) Urb. (Apiceae) has potential cytotoxic and antitumor qualities by prevention of carcinogenesis through modulation of the immune response. Data show the immunostimulating activity of the water extract of this plant on mitogen-stimulated proliferation of human peripheral blood mononuclear cells (Punturee et al., 2005). Allium sativum (L.) Rchb. (Alliaceae) inhibit tumor growth by activation of natural killer and T cells, along with increased IL-2 secretion (Morioka et al., 1993). Anrographis paniculata Burm. F. (Acanthaceae) is a potent stimulator of the immune system by increasing antibody synthesis and delayed type hypersensitivity. Compounds isolated from this plant have also shown anticancer activities (Kumar et al., 2004).

In our previous studies, we reported the immunostimulatory effects of the extracts of several native medicinal plants from the Euphorbia genus on lymphocyte proliferation and their inhibitory effects on tumor cells (Amirghofran et al., 2006, 2011). We showed that the tumor growth inhibitory effect of one of these plants, E. cheradenia Boiss. and Hohen. (Euphorbiaceae) was through induction of apoptosis in leukemia cell lines (Amirghofran et al., 2006). The genus Euphorbia called "Farfioun" in Persian comprises more than 2,000 species. This is the largest in the spurge family (Euphorbiaceae) where nearly 70 species grow in Iran, 17 of which are endemic (Pahlevani, 2007). Studies have revealed the presence of diterpenes, flavonoids, sterols, tannins, and triterpenes as the major bioactive constituents of these plants (Jassbi, 2006). The compounds isolated from the genus Euphorbia and its extracts perform a number of different biological activities- antiproliferative, cytotoxic, antimicrobial and anti-inflammatory, anticancer and antioxidant (Ozbilgin and Citoglu, 2012). In the present study, we have focused on the antitumor and immunomodulatory effects of extracts from two native species of Euphorbia (E. hebecarpa Boiss and Euphorbia petiolata Banks and Sol.) that are traditionally used for treatment of cancer and various infections according to folk medicine (Bajaj, 1994). E. hebecarpa have a restricted growth distribution, being confined to the extreme north of Iraq and Western Iran (Radcliffe-Smith, 1985). E. petiolata is mainly located in the Azerbaijan region, Northwest Iran. This plant is locally used for treating warts, dermatitis, fungal infections, and tumors. Previous phytochemical studies on this species have shown the presence of ingenane-type diterpenes and triterpenes, as well as flavonoid glycosides such as myricetin, kaempferol, and quercetin that have free radical scavenging activity (Nazemiyeh et al., 2010).

We aimed to determine the possible influence of these plants on the induction of apoptosis in tumor cell lines and to determine their immunomodulatory effects on the cytokine secretion pattern in treatment of human peripheral blood lymphocytes (PBLs). The data obtained would be useful to find the principal mechanisms responsible for the immunomodulatory and antitumor activities of these plants.

\section{Materials and Method}

\section{Preparation of the extract}

Aerial parts of the plants were collected from Fars province and authenticated by Dr. Khosravi from Department of Biology, Shiraz University, Shiraz, Iran. Voucher specimens were deposited in the Shiraz University Herbarium. A methanol extract from each plant was obtained as previously described (Amirghofran et al., 2011). The yield (w/w) of the extract was $7.4 \%$ for E. hebecarpa and $8.5 \%$ for E. petiolata. The methanol extracts were then suspended in water and successively re-extracted by hexane and butanol. The preparation of butanol and hexane extracts from the plants was based on the results of our previous study in which the hexane extract of both plants had shown the highest growth inhibitory effects on tumor cell lines. The same extract from E. petioleta and the butanolic extract of $E$. hebecarpa had shown the highest proliferatory effects on PBLs (Amirghofran et al., 2011). The extracts were then concentrated under reduced pressure using a rotary evaporator and then freeze-dried. For the bioassay tests, extracts were dissolved in dimethyl sulfoxide (DMSO, Sigma, St. Louis, MO) and then diluted in RPMI 1640 culture medium (Sigma).

\section{Cell lines and cell cultures}

The tumor cell lines including HeLa (cervix epitheloid carcinoma) and K562 (myelogenous leukemia) were obtained from Pasteur Institute of Iran. In this center the cell lines are routinely authenticated by Short Tandem Repeat (STR) technique. In our previous screening on the growth inhibitory effects of the extracts on various tumor cell lines, the above cells had shown the highest sensitivity for E. hebecarpa and E. petiolata, respectively. These cells were kept in RPMI 1640 medium supplemented with 10\% fetal calf serum (Gibco-BRL, Germany) in culture flasks at $37^{\circ} \mathrm{C}$ in a $5 \%$ humidified $\mathrm{CO}_{2}$ incubator. The cells were expanded by trypsinization (for HeLa adherent cells) and subcultured at lower numbers in new culture flasks. For the experiments, the viability of cells determined by trypan blue was more than $95 \%$.

\section{Flow cytometry analysis}

Annexin $\mathrm{V}$ and propidium iodide (PI) staining was used to study the apoptosis-inducing effect of the plants hexane extracts on HeLa and K562 and cell lines by flow cytometry. Studied concentrations were chosen 
according to the results of MTT [3-(4,5-dimethylthiazoyl2,5-diphenyltetrazolium bromide] viability assay in our previous study (Amirghofran et al., 2011). The experiments were performed according to an annexin V/PI kit from IQ product, Netherland. HeLa cells at concentration of 7500/well and K562 at 15,000 cells/well were treated with $10-200 \mu \mathrm{g} / \mathrm{ml}$ of the extracts for $24 \mathrm{~h}$ at $37^{\circ} \mathrm{C}$ and $5 \% \mathrm{CO}_{2}$. The binding buffer saturated with annexin V-FITC was added for $20 \mathrm{~min}$ at $4^{\circ} \mathrm{C}$ in the dark. To discriminate between early apoptosis and late apoptosis, the cells were simultaneously stained with annexin V and PI before analysis. The binding of annexin $\mathrm{V}$ and PI to the cells was measured by flow cytometry (FACSCalibur, BD Biosciences, San Jose, CA) and the data was analyzed by FlowJo7.6 software (Tree Star, Inc., Ashland, OR). A concentration of $50 \mu \mathrm{g} / \mathrm{ml}$ cisplatin was used as positive control and cells treated with no extract containing DMSO at the highest concentration used in the test wells (e.g, $0.1 \%$ ) were considered as negative control. At least 10,000 cells were counted in each sample. Cells that were Annexin V positive and PI negative were considered as early apoptotic cells and those with Annexin $\mathrm{V}$ positive and PI positive as late apoptotic cells. The total of early and late apoptosis was considered as percentage of apoptosis. All experiments were performed in triplicate and repeated at least three times.

\section{Caspase 3 colorimetric assay}

The cell lines were cultured in the presence of the extracts for $24 \mathrm{~h}$. Cells treated with $50 \mu \mathrm{g} / \mathrm{ml}$ cisplatin was considered as positive control and cells treated only with DMSO (0.05\%) considered as negative control. The enzymatic activity of caspase 3 was determined by caspase colorimetric assay kit (R\&D Systems Inc., Minneapolis, MN) according to the manufacturer's instructions. In brief, cells were treated by ice-cold lysis buffer for $10 \mathrm{~min}$ to extract cytosolic compartment. After removal of cellular debris by centrifugation, protein levels were determined by Bradford method (Bio-Rad, Hercules, CA) and equalized accordingly to obtain 2- 4 $\mathrm{mg} / \mathrm{ml}$ of cytosolic extract per sample. Samples were incubated at $37^{\circ} \mathrm{C}$ for $2 \mathrm{~h}$ with $5 \mu \mathrm{l}$ caspase 3 substrate DEVD- $\mathrm{p}$-nitroanilide ( $p$ NA). Upon cleavage of the substrate by caspase 3 , free $p$ NA light emission was quantified using a microplate reader (Biotek, Winooski, VT) at $405 \mathrm{~nm}$. The absorbance of $p$ NA from treated cells were compared with the negative control and the fold changes in caspase 3 activity relative to the value of negative control (RFC) was determined.

\section{Real-time polymerase chain reaction (PCR)}

The cell lines were cultured in the presence of the extracts for $24 \mathrm{~h}$. After cell harvesting, total RNA was extracted using the Total RNA Extraction Kit (Pars tous Biotechnology, Tehran) according to the manufacturer's instructions. Total RNA quality was evaluated using agarose gel electrophoresis and was quantified via a Nanodrop 1,000 spectrophotometry (Thermo Scientific, Wilmington, DE). Extracted RNA $(1 \mu \mathrm{g})$ was reverse transcribed with random primer to double-strand cDNA using High-Capacity cDNA Reverse Transcription Kit
(Applied Biosystems, Foster City, CA). Real-time PCR performed using Takara SYBR Premix Ex taq II (Bio Inc., Japan) in duplicate. The levels of mRNA expression of B-cell lymphoma (Bcl)-2 ( $\beta$ isoform), Bax, Fas (membrane bound isoforms) and $\beta$-actin, a housekeeping gene that was used as an internal control, was detected by Step One Real-Time PCR (Applied Biosystems). The sequences of primers designed by AlleleID 6 software (Biosoft, San Diego, CA) and blasted in NCBI BLAST as previously described (Ebrahimnezhad Darzi and Amirghofran, 2013). The PCR conditions for amplification of cDNA were $95^{\circ} \mathrm{C}$ for $30 \mathrm{~s}$ followed by denaturing at $95^{\circ} \mathrm{C}$ for $5 \mathrm{~s}$, annealing at $57^{\circ} \mathrm{C}\left(\beta\right.$-actin, Fas) and $54^{\circ} \mathrm{C}(\mathrm{Bax}$ and Bcl-2) for $15 \mathrm{~s}$ and extension at $72^{\circ} \mathrm{C}$ for $30 \mathrm{~s}$ for 40 cycles.

Reaction with water instead of cDNA template was considered as a non-template control. The amplified PCR product was electrophoresed through 1.5\% agarose gel. Data were analysed by the $2^{-\Delta \Delta \mathrm{Ct}}$ method. Results of target mRNA levels were normalized against $\beta$-actin mRNA in each sample. All target genes results were shown as relative fold change (RFC) to the negative control.

\section{Lymphocyte proliferation assay}

Blood was obtained from five healthy male individuals (25-35 years, with their consent); PBLs were isolated by gradient centrifugation on Ficoll-hypaque (Sigma). The viability of cells determined by trypan blue staining was more than $95 \% .10 \mu \mathrm{l}$ of phytohemagglutinin (PHA) as the mitogen $(1 / 1,750$, Fluka, Germany) was added to the culture of PBLs $\left(1 \times 10^{5}\right.$ cells $/ 90 \mu \mathrm{l} /$ well $)$ in flat-bottom 96-well plates. Cells were incubated at $37^{\circ} \mathrm{C}$ and $5 \%$ $\mathrm{CO}_{2}$ in a humidified incubator for $48 \mathrm{~h}$ in the presence or absence of various concentrations $(0.1-10 \mu \mathrm{g} / \mathrm{ml})$ of the E. hebecarpa butanolic extract and E. petioleta hexane extract. In order to find the possible direct stimulatory activity of the extracts on lymphocytes, the effect of the extracts on PBLs in the absence of PHA was also investigated. Positive control was extract-untreated cells stimulated with PHA and negative control was cells without the extract and PHA. In all wells without the extract, DMSO as the solvent at the highest concentration used in the tests (e.g., $0.01 \%$ ) was added. The proliferation of cells was determined by a 5-bromo-2'-deoxy-uridine (BrdU) incorporation assay kit (Roche, Germany) as described previously (Amirghofran et al., 2012). Briefly, after addition of BrdU to the cultures and an incubation for $18 \mathrm{~h}$, DNA was denatured and the cells were incubated with anti-BrdU monoclonal antibody for detecting incorporated BrdU. The measurement of the absorbance related to the BrdU level was done by a microplate reader at $450 \mathrm{~nm}$. The results was shown by the proliferation of PBLs compared to the positive control (for cultures in the presence of PHA) and to negative control (for cultures in the absence of PHA) taken to be $100 \%$. All experiments were performed in triplicate and repeated at least three times. The same experiments with the similar conditions were performed in parallel to collect the supernatant of the cells for measurement of cytokines.

\section{Measurement of cytokines}

Measurment of cytokines in the supernatant of 
extract-treated cultures with the highest proliferatory effect on the PBLs were determined by using ELISA kits for interferon (IFN)- $\gamma$, Interleukin (IL)-4, IL10 and IL-17 (eBioscience, Germany). The sensitivity of the kits was equal or less than $4 \mathrm{pg} / \mathrm{ml}$. After coating the plate with capture antibody at $4^{\circ} \mathrm{C}$ for an overnight, the wells were washed by buffer and then covered by blocking protein for $1 \mathrm{~h}$ at room temperature (RT). After washing, standards and samples were added and the plate incubated at $4{ }^{\circ} \mathrm{C}$ for an overnight. The detection antibody was added for $1 \mathrm{~h}$ at RT, the supernatant was aspirated and then Avidin-horseradish peroxidase (HRP) solution was added. The plate was incubated for $30 \mathrm{~min}$ at RT after which the substrate solution was added and then the reaction stopped by addition of the stopping solution after $15 \mathrm{~min}$. The absorbance at $450 \mathrm{~nm}$ was measured by an ELISA reader (Biotek) and the level of each cytokine was determined through the standard curve.

\section{Statistical analysis}

The data were presented as mean \pm standard deviation (SD) and the assessment between the groups was analyzed by appropriate statistical tests, e.g. one-way analysis of variance (ANOVA) and a Student's t-test in GraphPad, Prism 5 software (San Diego, CA). The level of significance was set at $p<0.05$.

\section{Results}

The effect of Euphorbia extracts on apoptosis induction

We examined the possible effects of the plants' hexane extracts on apoptosis induction by flow cytometry and annexin V/PI staining. E. hebecarpa, at concentrations of $10-100 \mu \mathrm{g} / \mathrm{ml}$ induced a dose-dependent apoptosis in HeLa cancer cells (Figure 1). This effect increased from $63.9 \pm 15.7 \%(p<0.05)$ at the $10 \mu \mathrm{g} / \mathrm{ml}$ concentration, $80.4 \pm 14.2 \%$ at $50 \mu \mathrm{g} / \mathrm{ml}(p<0.01)$, and $98.5 \pm 0.1 \%$ at the $100 \mu \mathrm{g} / \mathrm{ml}(p<0.01)$ concentration compared to the negative control $(18.2 \pm 12.8 \%)$. E. petiolata also showed a significant apoptosis-inducing effect on
K562 cells (Figure 1) that ranged from $53 \pm 7 \%$ at the $50 \mu \mathrm{g} / \mathrm{ml}$ concentration to $83.6 \pm 0.1 \%$ at the $200 \mu \mathrm{g} / \mathrm{ml}$ concentration compared to the negative control $(p<0.05)$. The representative flow cytometry dot plots of the induced apoptosis for both extracts are shown in Figure 2A, 2B.

\section{The effect of Euphorbia extracts on caspase 3 activity}

The effect of E. hebecarpa extract on HeLa and E. petiolata extract on K562 cells was examined for caspase 3 activity. As shown in Figure 3, E. hebecarpa extract increased caspase 3 activity at both concentrations of $10 \mu \mathrm{g} / \mathrm{ml}(2.4 \pm 0.1 \mathrm{RFC}, p<0.001)$ and $50 \mu \mathrm{g} / \mathrm{ml}$ $(2.7 \pm 0.1 \mathrm{RFC}, p<0.001)$. E. petiolata extract also enhanced caspase activity to $1.8 \pm 0.15 \mathrm{RFC}$ at $50 \mu \mathrm{g} / \mathrm{ml}$ $(p<0.01)$ and $2.8 \pm 0.1 \mathrm{RFC}$ at $100 \mu \mathrm{g} / \mathrm{ml}(p<0.001)$. Cisplatin, as the positive control, caused a greater than 4-fold increase in caspase 3 activity in both HeLa and K562 cells $(p<0.001)$.

The effect of Euphorbia extracts on apoptosis-related gene expressions

We used real-time PCR to examine the effects of E. hebecarpa and E. petiolata extracts on the key apoptosis-related genes of Fas, Bax and Bcl-2 in HeLa (for E. hebecarpa) and K562 cells (for E. petiolata). As seen in Figure 4A, E. hebecarpa extract significantly increased Fas gene expression at both concentrations of $10 \mu \mathrm{g} / \mathrm{ml}$ $(2.07 \pm 0.24 \mathrm{RFC}, p<0.01)$ and $50 \mu \mathrm{g} / \mathrm{ml}(5.27 \pm 0.17$ RFC, $p<0.001)$. This extract at both concentrations upregulated Bax gene expression $(>4.6$ RFC, $p<0.001$; Figure 4B). In contrast, treatment of HeLa cells with $E$. hebecarpa extract led to a significant downregulation of Bcl-2 gene expression at $50 \mu \mathrm{g} / \mathrm{ml}(0.40 \pm 0.03 \mathrm{RFC}$, $\mathrm{p}<0.001$; Figure $4 \mathrm{C}$ ). The Bax/Bcl-2 ratio at 10 and 50 $\mu \mathrm{g} / \mathrm{ml}$ of the E. hebecarpa extract displayed an increased ratio, which favored apoptosis induction. This ratio at 10 $\mu \mathrm{g} / \mathrm{ml}$ of the extract was $5.15 \pm 0.06(\mathrm{p}<0.001)$, which increased to $17.87 \pm 0.24(\mathrm{p}<0.001)$ at $50 \mu \mathrm{g} / \mathrm{ml}$. In comparison, the anticancer drug cisplatin at $50 \mu \mathrm{g} / \mathrm{ml}$ slightly increased Fas and $\operatorname{Bax}(>1.5$ RFC, p > 0.05)
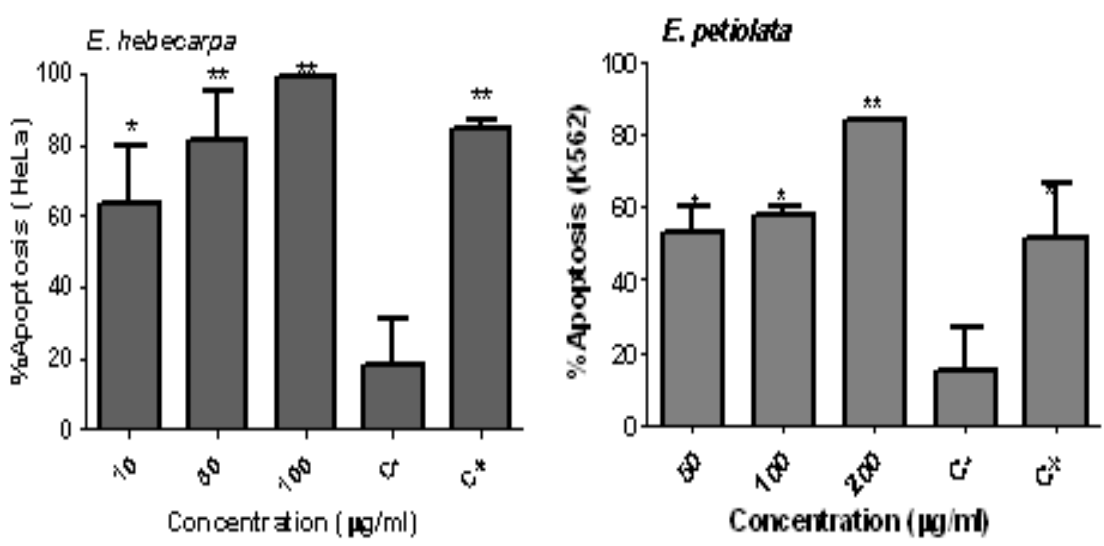

Figure 1. Apoptosis-Inducing Effect of E. hebecarpa and E .petiolata Extracts on HeLa and K562 Cells. Cells were treated with various concentrations of the extracts for $24 \mathrm{~h}$ and then annexin V/PI staining was performed. Positive control $(\mathrm{C}+)$ was cells treated with $50 \mu \mathrm{g} / \mathrm{ml}$ cisplatin and negative control $(\mathrm{C}-)$ was extract-untreated cells containing DMSO at the highest concentration used in the test wells (e.g., $0.1 \%$ ). The error bar is the standard deviation of the means between three different experiments. Asterisks show significant difference with the negative control. ${ }^{*} \mathrm{p}<0.05$, $* * \mathrm{p}<0.01$ compared to negative control. 
A

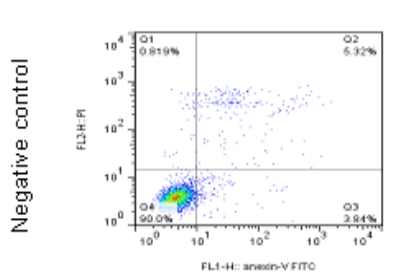

E. hebecarpa
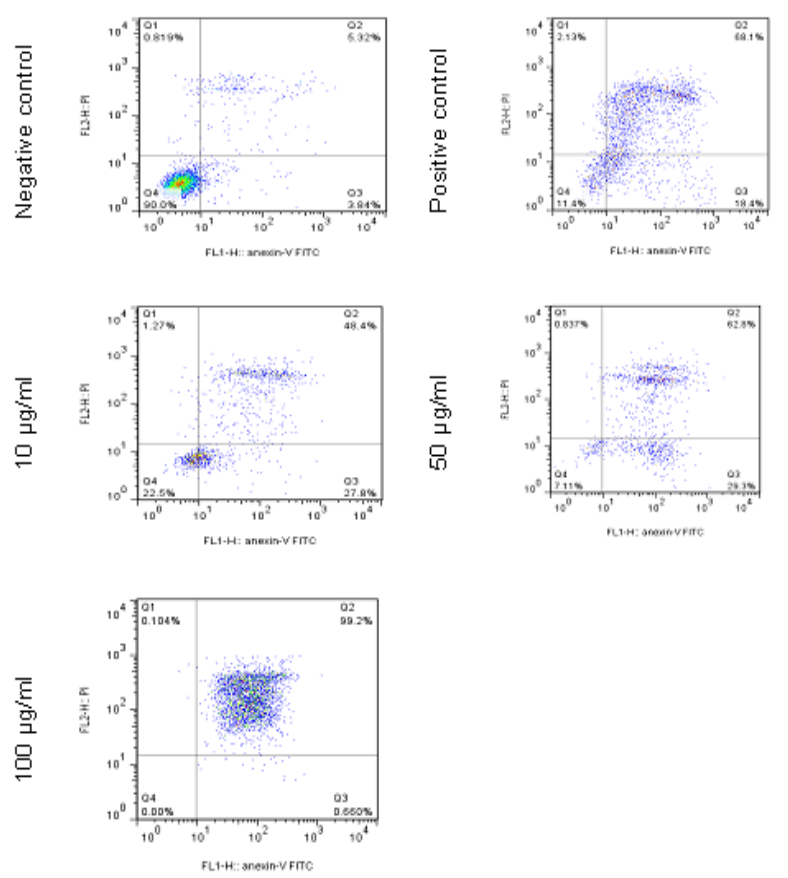

B

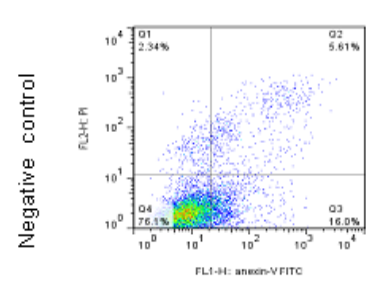

E. petiolata
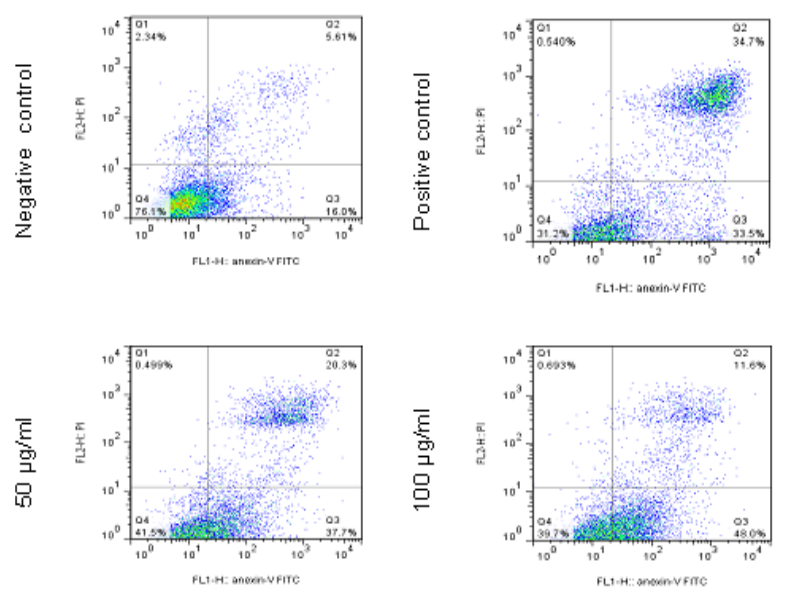

Figure 2. The Flow Cytometry Dot Plots Representing the Apoptosis-Inducing Effect of the Hexane Extracts of E. hebecarpa on HeLa Cell Line (A) and E. petiolata on K562 cell line (B). Cells were treated with various concentrations of the extract for $24 \mathrm{~h}$ and then annexin V/PI staining was performed. Positive control was cells treated with $50 \mu \mathrm{g} / \mathrm{ml}$ cisplatin and negative control was extract-untreated cells containing DMSO at the highest concentration used in the test wells (e.g., $0.1 \%$ ). The total of early and late apoptosis was considered as percentage of apoptosis. The result shown is one representative experiment out of three independent experiments.

mRNA expressions in HeLa cells but significantly decreased Bcl-2 expression $(\approx 0.47 \mathrm{RFC}, \mathrm{p}<0.001)$. The resultant $\mathrm{Bax} / \mathrm{Bcl}-2$ ratio for this drug was $3.46 \pm 0.58$ (Figure 4D).

E. petiolata increased expression of Fas in $\mathrm{K} 562$ cells at the $50 \mu \mathrm{g} / \mathrm{ml}(1.73 \pm 0.15 \mathrm{RFC}, \mathrm{p}<0.05)$ and $100 \mu \mathrm{g} /$ $\mathrm{ml}(2.31 \pm 0.02, \mathrm{p}<0.01)$ concentrations (Figure 4E). Bax gene expression upregulated to $3.32 \pm 0.39$ RFC $(\mathrm{p}<0.01)$ at the $100 \mu \mathrm{g} / \mathrm{ml}$ concentration of this extract (Figure 4F). Treatment of K562 cells with this extract markedly diminished Bcl-2 expression (Figure 4G). The
$\mathrm{Bax} / \mathrm{Bcl}-2$ ratio increased to $26.42 \pm 0.58(\mathrm{p}<0.01)$ at 50 $\mu \mathrm{g} / \mathrm{ml}$ and $38.69 \pm 5.57(\mathrm{p}<0.01)$ at $100 \mu \mathrm{g} / \mathrm{ml}$ of the extract. Comparatively, cisplatin increased Fas and Bax $(>2.6$ RFC, $p<0.01)$ and decreased Bcl-2 expression $(0.31$ \pm 0.1 RFC, $\mathrm{p}<0.01$ ) in K562 cells (Figures 4E-4G). The resultant $\mathrm{Bax} / \mathrm{Bcl}-2$ ratio for this drug was $11.38 \pm 3.67$ $(\mathrm{p}<0.05$; Figure $4 \mathrm{H})$.

The effect of Euphorbia extracts on lymphocyte proliferation

We examined the effects of the E. hebecarpa
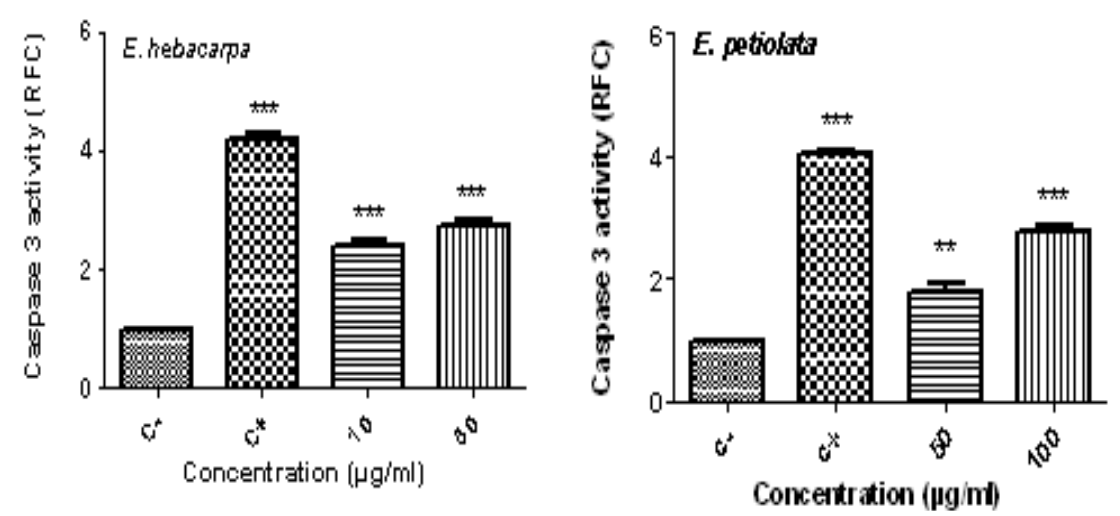

Figure 3. Effect of the Extracts on Caspase 3 Activity. HeLa cells were treated with the E. hebecarpa extract and K562 cells with $E$. petiolata extract. After $24 \mathrm{~h}$ the caspase activity was examined by colorimetric assay. Positive control $(\mathrm{C}+$ ) was cells treated with $50 \mu \mathrm{g} / \mathrm{ml}$ cisplatin and negative control $(\mathrm{C}-)$ was extract-untreated cells containing DMSO at the highest concentration used in the test wells (e.g., $0.05 \%$ ). Data represent fold changes in caspase 3 activity relative to negative control (RFC). The error bar is the standard deviation of the means between three different experiments. $* * p<0.01$ and $* * * p<0.001$ compared to negative control. 

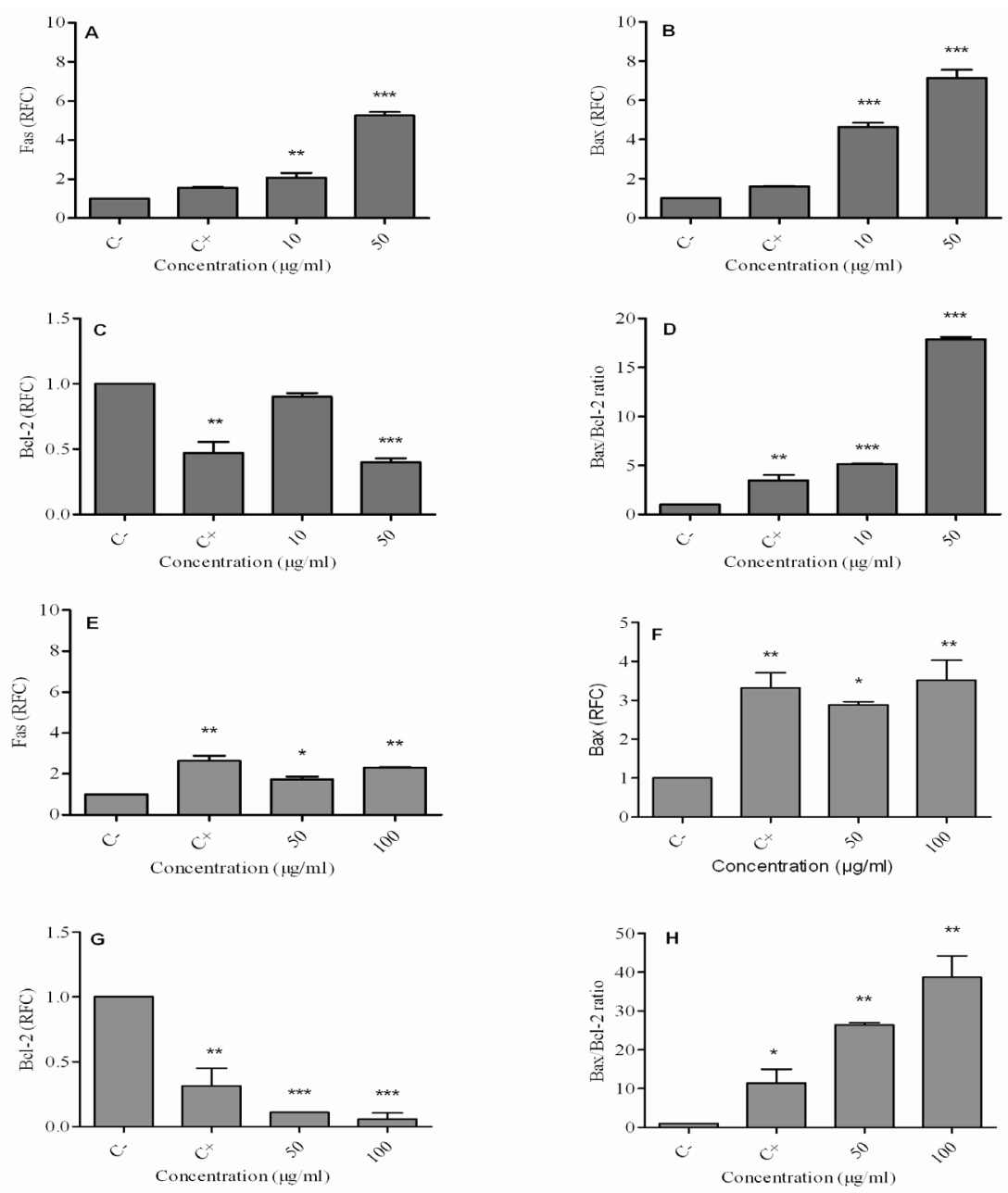

Figure 4. Effect of Different Concentrations of the Extracts on the Gene Expressions of Fas and Bax Apoptosis Promoting and Bcl-2 Antiapoptotic Molecules. HeLa cells were treated with E. hebacarpa (A-D) and K562 cells treated with $E$. petiolata extract $(\mathrm{E}-\mathrm{H})$ for $24 \mathrm{~h}$ and then gene expressions were analyzed by real time-PCR (A). Positive control (C+) was cells treated with $50 \mu \mathrm{g} / \mathrm{ml}$ cisplatin and negative control (C-) was extract-untreated cells containing DMSO at the highest concentration used in the test wells (e.g., $0.05 \%$ ). The error bar is the standard deviation of the means between at least two different experiments. $* p<0.05, * * p<0.01$ and $* * * p<0.001$ compared to negative control.

butanolic extract and the hexane extract of E. petiolata on lymphocyte proliferation in the presence and absence of mitogen. Figure 5A1 shows that the E. hebecarpa extract stimulated lymphocyte proliferation. In comparison with the positive control, this effect was significant at $1 \mu \mathrm{g} /$ $\mathrm{ml}(138.6 \pm 8.2 \%$ of the control; $\mathrm{p}<0.05)$. The extract at concentrations of $0.1-10 \mu \mathrm{g} / \mathrm{ml}$ caused lymphocyte proliferation in the absence of PHA $(p<0.05$; Figure 5A2).

The $10 \mu \mathrm{g} / \mathrm{ml}$ concentration of the E. petiolata hexane extract in the presence of mitogen significantly increased lymphocyte proliferation compared with the positive control ( $p<0.01$; Figure 5B1). As shown in Figure 5B2, treatment of PBLs with $1-10 \mu \mathrm{g} / \mathrm{ml}$ of this extract in the absence of PHA stimulated lymphocyte proliferation ( $p$ $<0.01)$.

The effect of the Euphorbia extracts on cytokine secretion

We measured the effects of these plant extracts on the production of different cytokines in the supernatants of cultures with various treatments. Figure 6A1 shows changes in IFN- $\gamma$ production by the lymphocytes due to exposure with the extracts in the presence of PHA. Both E. hebecarpa $(508 \pm 25 \mathrm{pg} / \mathrm{ml})$ and E. petiolata $(470 \pm$ $1.4 \mathrm{pg} / \mathrm{ml})$ significantly increased IFN- $\gamma(\mathrm{p}<0.05)$. In the absence of PHA, the plants also increased the IFN- $\gamma$ production (Figure 6A2).

Both plants significantly increased IL-4 in the presence of PHA (Figure 6B1). In this regard, E. petiolata seemed to be stronger than E. hebecarpa as the level of IL-4 secretion by cells in the presence of E. petiolata $(105 \pm 1.4 \mathrm{pg} / \mathrm{ml})$ was greater than in the presence of E. hebecarpa $(26.9 \pm 0.6 \mathrm{pg} / \mathrm{ml})$. We assessed the effects of these plants on IL-4 production by lymphocytes in the absence of PHA. Compared to the negative control, neither of the plants changed the amount of secretory IL-4 (Figure 6B2). As seen in Figure 6C1, E. hebecarpa and $E$. petiolata significantly decreased IL-10 secretion by mitogen-stimulated lymphocytes. These plants in the absence of PHA also reduced IL-10 levels compared to the negative control (Figure 6C2). The effect of the plants on the production of IL-17 by lymphocytes in the presence or absence of PHA was also investigated. E. hebecarpa 

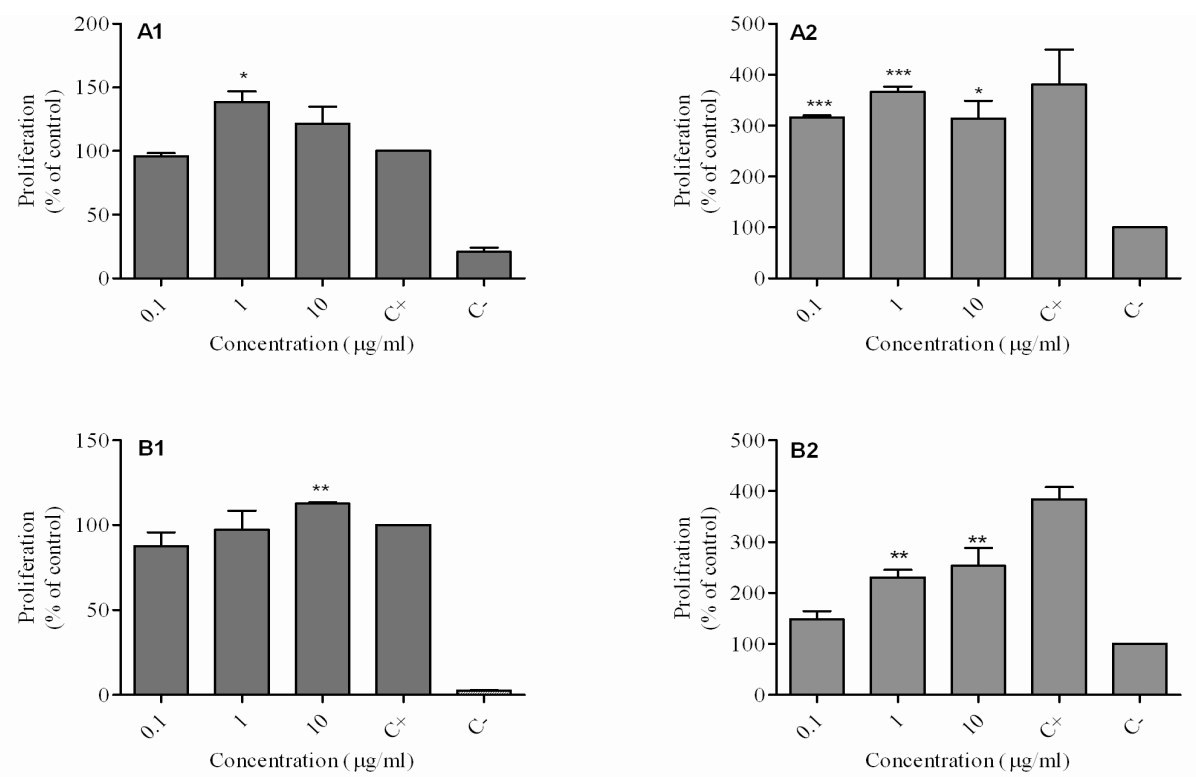

Figure 5. The Effect of E. hebecarpa (A) and E. petiolata (B) Extracts on the Stimulation of Human Peripheral Blood Lymphocytes in the Presence (1) and Absence (2) of PHA. Cells were cultured with different concentrations of the extracts for $48 \mathrm{~h}$ and then cell proliferation was measured by Brdu incorporation assay. Positive control $(\mathrm{C}+)$ was lymphocytes treated only with PHA and without the extracts and negative control (C-) was those without PHA and the extracts. The asterisks show significant difference with positive control (for cultures in the presence of PHA; A1, B1) and with negative control (for cultures in the absence of PHA; A2, B2). The error bar is the standard deviation of the means between three different experiments. ${ }^{*} \mathrm{p}<0.05,{ }^{*} \mathrm{p}<0.01, * * * \mathrm{p}<0.001$.
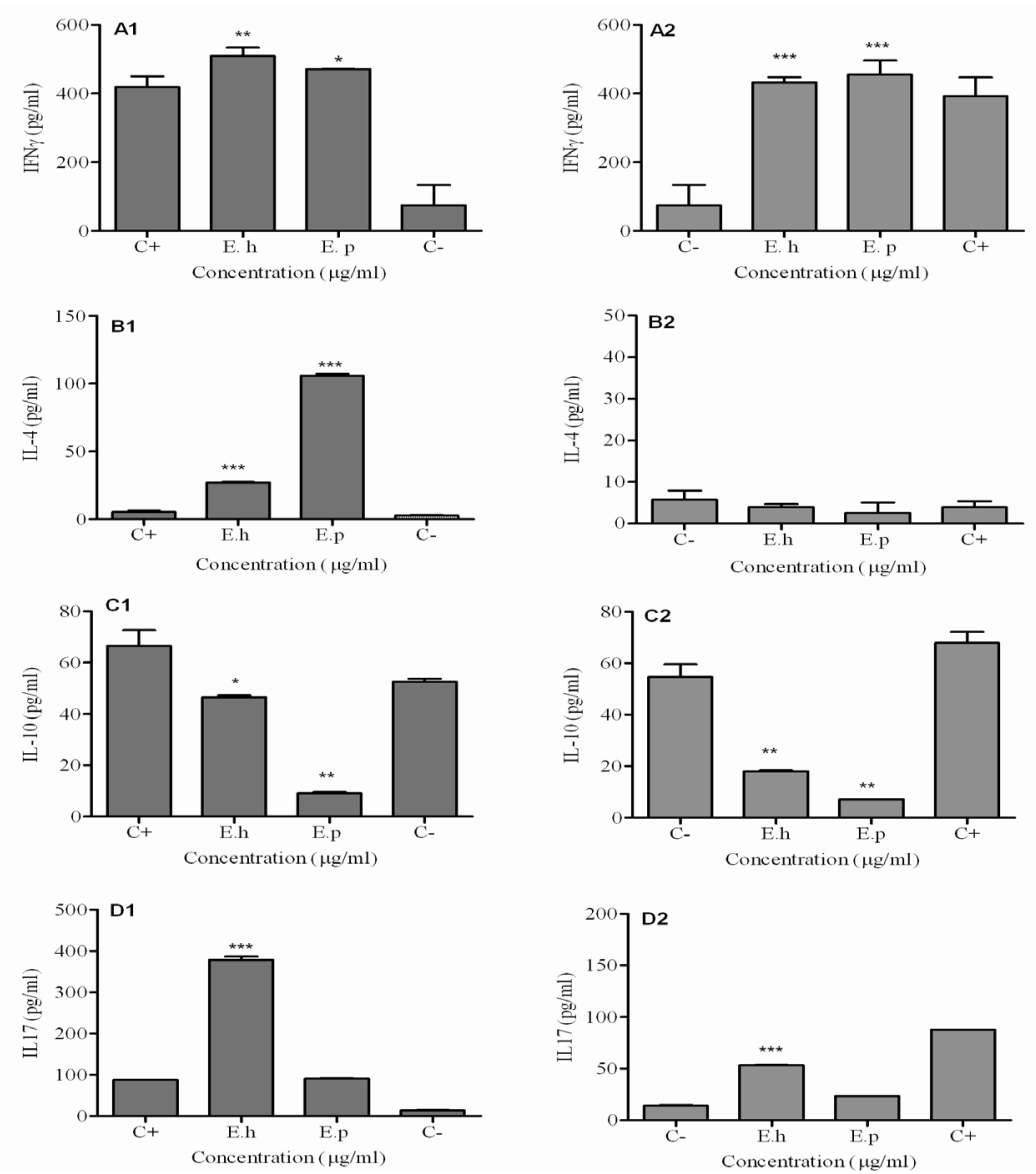

Figure 6. The effect of $1 \mu \mathrm{g} / \mathrm{ml}$ E. hebecarpa (E.h) and $10 \mu \mathrm{g} / \mathrm{ml}$ E. petiolata (E.p) extracts on production of IFN- $\gamma$ (A), IL-4 (B), IL-10 (C) and IL-17 (D) by human peripheral blood lymphocytes in the presence (1) and absence (2) of PHA. Cells were cultured with different concentrations of the extracts for $48 \mathrm{~h}$ and the supernatants was collected and assayed by ELISA. Positive control $(\mathrm{C}+)$ was lymphocytes treated only with PHA and without the extracts and negative control (C-) was those without PHA and the extracts. The error bar is the standard deviation of the means between at least two different experiments. The asterisks show significant difference with positive control (for cultures in the presence of PHA; A1, B1, C1, D1) and with negative control (for cultures in the absence of PHA; A2, $\mathrm{B} 2, \mathrm{C} 2, \mathrm{D} 2) .{ }^{*} \mathrm{p}<0.05, * * \mathrm{p}<0.01, * * * \mathrm{p}<0.001$. 
significantly increased IL-17 release. Compared to the positive control, E. petiolata had no significant effect on IL-17 secretion (Figure 6D1). A similar result was obtained for IL-17 production in the absence of PHA (Figure 6D2).

\section{Discussion}

Cancer is considered a serious disease characterized by abnormal or uncontrolled cell growth. Plants have been a prime source of natural products for the treatment of various diseases, particularly cancers. Many conventional cancer drugs have been initially derived from plants (Srancikova et al. 2013). The most important drawback of the current cancer therapeutic practices such as chemotherapy and radiation therapy is suppression of the immune system (Li et al., 2013). Research has shown that the immune system is an active participant in defense against tumors by exertion of various antitumor activities. Therefore, plants that have the ability to enhance immune response in addition to antitumor effects can be ideal candidates for anticancer therapy. The Euphorbia plants studied here have shown both of these effects. In an attempt to screen the growth inhibitory effects of several Euphorbia species, we found the strongest effects of E. hebecarpa on HeLa cells and E. petiolata on K562 cells (Amirghofran et al., 2011). These plants also effectively enhanced lymphocyte proliferation in the presence of mitogen.In the current study, we first investigated whether the capability of E. hebecarpa and E. petiolata to inhibit tumor cell growth was due to induction of apoptosis. Apoptosis is an active process in which DNA is damaged and the cell dies without generating inflammation (Mognol et al., 2016). Therefore, medicines and compounds which can promote their anticancer activities through apoptosis are valuable candidates for cancer therapy (Kontos et al., 2013). As the results of annexin V/PI staining have shown, both extracts induced apoptosis in the cancer cell lines. Regardless of cell type, E. hebecarpa appeared to have a stronger effect. This extract dose-dependently induced apoptosis in HeLa cells with maximum activity at $100 \mu \mathrm{g} /$ $\mathrm{ml}$ where approximately $98 \%$ of the cells underwent apoptosis compared to E. petiolata extract which had a maximum activity of approximately $83 \%$ at $200 \mu \mathrm{g} / \mathrm{ml}$.

During the cascade of events associated with apoptosis, various molecules including caspases are activated (Ziaei et al., 2011; Tian et al., 2016). These proteins are crucial mediators of programmed cell death, among which caspase 3 is an intracellular cysteine protease. In its activated form caspase 3 can catalyze the specific cleavage of many key cellular proteins. This central role of caspase 3 in the apoptosis process makes it an important target for cancer therapy (Xie et al., 2015). We have examined the activation of this molecule following treatment of tumor cell lines with the extracts. Treatment of HeLa cells with E. hebecarpa extract and K562 cells with E. petiolata extract caused increased activation of caspase 3 compared to untreated cells. These results confirmed the flow cytometry results and supported the apoptosis inducing activity of the extracts in a caspase 3-dependent manner.

Apoptosis induction occurs via two pathways, extrinsic and intrinsic (Siddiqui et al., 2015; Arasteh et al., 2010). The extrinsic pathway is initiated by stimulation of the death receptors (e.g., Fas) in the plasma membrane and formation of death inducing signaling complex (DISC) in the presence of Fas-associated death domain and procaspase-8. In the intrinsic pathway two molecules (Bax and Bcl-2) are the main players (Banerjee et al., 2016). The pro-apoptotic effect of Bax can trigger and accelerate mitochondrial permeabilization resulting in cytochrome $\mathrm{C}$ release and apoptosis induction. Bcl-2 is an anti-apoptotic molecule that inhibits apoptosis by preserving the mitochondrial membrane (Amirghofran et al., 2004). We have used real-time PCR to determine the effects of the extracts on the gene expressions of Fas, Bax and Bcl-2 molecules. Our results showed upregulation of the Fas gene by both extracts. E. hebecarpa extract increased Bax proapoptotic gene expression in HeLa cells at both concentrations used and decreased Bcl-2 at $50 \mu \mathrm{g} /$ $\mathrm{ml}$. Similarly, E. petiolata treatment of K562 cells resulted in upregulationof Bax expression and downregulation of Bcl-2 gene expression at both concentrations. These data suggested apoptosis induction to be the underlying mechanism of tumor cell growth inhibition in the studied plants and implied a possible involvement of both extrinsic and intrinsic pathways in this process.It has been shown that an increased $\mathrm{Bax} / \mathrm{Bcl}-2$ ratio correlated with upregulation of caspase 3 and increased apoptosis (Salakou et al., 2007). Thus, modulation of Bax/Bcl-2 ratio might be more important than expression alone in determining apoptosis. As our results showed, both the extracts increased this ratio. This effect was stronger than the effect of cisplatin. The ability of the extract to modulate the $\mathrm{Bax} / \mathrm{Bcl} 2$ ratio might suggest their possible application in regulation of apoptosis in tumor cells.

The lymphocyte proliferation assay showed that in the presence of PHA both E. hebecarpa and E. petiolata enhanced lymphocyte proliferation. At all concentrations, E. hebecarpa enhanced lymphocyte proliferation in the absence of PHA which implied its potential mitogenic activity. Similarly, E. petiolata at concentrations of 1-10 $\mu \mathrm{g} / \mathrm{ml}$ have shown significant mitogenic effects on the lymphocytes. When naive $\mathrm{T}$ helper cells encounter an antigen or mitogen they activate and can differentiate into various subsets with different cytokine profiles and effector functions, including Th1, Th2, and Th17 cells (Geginat et al., 2013). Th1 cells primarily secrete IFN- $\gamma$ proinflammatory cytokines and are involved in cell-mediated immunity, whereas Th2 cells produce mainly IL-4 anti-inflammatory cytokines and evoke humoral immunity (Romagnani, 2000). Th17 cells are the third subset of T helper cells that produce IL-17 cytokines where they have important roles in inflammation and recruitment of macrophages and neutrophils to the sites of inflammation (Muranaki and Restifo, 2013). In this study, we have sought to determine the level of $\mathrm{T}$ cell cytokines in the supernatants of the treated cells in order to find the dominant $\mathrm{T}$ cell subsets that responded to the extracts. Assessment of the changes in cytokines released from PHA-treated as well as -untreated lymphocytes in the presence of the Euphorbia plants showed increased levels of IFN- $\gamma$ and IL-4, along with decreased IL-10 
levels by E. hebecarpa. These data suggested the capability of E. hebecarpa to stimulate different subsets of T lymphocytes. With respect to $E$. petiolata, the increased cell proliferation was accompanied by increased levels of IFN- $\gamma$ and IL-4. However, compared to E. hebecarpa, this plant had a higher rate of lymphocyte stimulation for production of IL-4 in the presence of mitogen, which might show a greater enhancing effect on Th2-related responses. Increased levels of IFN- $\gamma$ and IL-4, along with the decreased level of IL-10 production by the lymphocytes exposed to E. petiolata might suggest that, the same as E. hebecarpa, this plant could have some immunostimulatory activity. This finding makes these plants suitable candidates for more studies in regards to their benefits as treatment for cancers and various infections.

We have observed that E. hebecarpa increased IL17 production. Although the function of Th17 secreting IL-17 in cancer immunity is controversial, adoptive T cell therapy with tumor-specific Th17 cells have been shown to prevent tumor development (Nunez et al., 2013). Th17 cells have an important role in cancer by promoting tumor-specific cytotoxic T cell activity, which is essential for the antitumor effect (Wu et al., 2013). The protective function of Th17 cells against tumors is also likely due to their ability to increase inflammatory responses, which lead to increased antigen presentation by dendritic cells (Martin-Orozco et al. 2009; Ghafourian Boroujerdnia et al., 2014)

In conclusion, this study showed that both $E$. hebecarpa and $E$. petiolata have antitumor effects by inducing apoptosis through intrinsic and extrinsic pathways in the selected cell lines. These plants also increased lymphocyte proliferation and stimulated secretion of different $T$ helper subset related cytokines. In this regard, E. hebecarpa with its increased effects on IFN- $\gamma$, IL-4, and IL-17 and decreased effect on IL-10 showed a capability to act as an immunostimulator. Although E. petiolata increased both IFN- $\gamma$ and IL-4 secretion, its ability to stimulate more IL-4 production than IFN- $\gamma$ implied a trend toward the Th2 pathway. The potential antitumor activity of these plants by their induction of apoptosis could also lead to enhancement of the immune response. This capability may be a potential research in regards to identification of active components, their mechanisms of action, and benefits as cancer therapy.

\section{Acknowledgments}

We would like to express our specific thanks to the Deputy of Research Affairs of Shiraz University of Sciences (grant no. 7204) and Ahvaz Jundishapur University of Medical Sciences (grant no. U-91254) for financial support.

\section{References}

Amirghofran Z, Bahmani M, Azadmehr A, Javidnia K (2006). Induction of apoptosis in leukemia cell lines by linum persicum and Euphorbia cheiradenia. J Cancer Res Clin Oncol, 132, 427-32.
Amirghofran Z, Bahmani M, Azadmehr A, Javidnia K (2007). Immunomodulatory and apoptotic effects of Stachys obtusicrena on proliferative lymphocytes. Med Sci Monit, 13, 145-50.

Amirghofran Z, Malek-Hosseini S, Gholmoghaddam H, Kalalinia F (2011). Inhibition of tumor cells growth and stimulation of lymphocytes by Euphorbia species. Immunopharmacol Immunotoxicol, 33, 34-42.

Amirghofran Z, Monabati A, Gholijani N (2004). Androgen receptor expression in relation to apoptosis and the expression of cell cycle related proteins in prostate cancer. Pathol Oncol Res, 10, 37-41.

Arasteh JM, Sarvestani EK, Aflaki E, Amirghofran Z (2010). Fas gene polymorphisms in systemic lupus erythematosus and serum levels of some apoptosis-related molecules. Immunol Invest, 39, 27-38.

Amirghofran Z, Ahmadi H, Karimi MH (2012). Immunomodulatory activity of the water extract of Thymus vulgaris, Thymus daenensis, and Zataria multiflora on dendritic cells and $\mathrm{T}$ cells responses. $J$ Immunoassay Immunochem, 33, 388-402.

Bajaj YPS (1994). Medicinal and aromatic plants VII. (Biotechnology in agriculture and forestry), vol 22. Springer-Verlag Berlin Heidelberg, pp 214.

Banerjee K, Basu S, Das S, et al (2016). Induction of intrinsic and extrinsic apoptosis through oxidative stress in drug-resistant cancer by a newly synthesized Schiff base copper chelate. Free Radic Res, 50, 426-46.

Cragg G, Newman D (2005). Plants as a source of anti-cancer agents. $J$ Ethnopharmacol, 100, 72-9.

Ebrahimnezhad-Darzi S, Amirghofran Z (2013). Dichloromethane fraction of Melissa officinalis induces apoptosis by activation of intrinsic and extrinsic pathways in human leukemia cell lines. Immunopharmacol Immunotoxicol, 35, 313-20.

Geginat J, Paroni M, Facciotti F, et al (2013). The CD4-centered universe of human T cell subset. Semin Immunol, 25, 252-62.

Ghafourian-Boroujerdnia M, Khosravi N, Malek-Hosseini S, Amirghofran Z (2014). Augmentation of lymphocytes activation and $\mathrm{T}$ cell modulation by the extracts from some Euphorbia species. Pharm Biol, 52, 1471-7.

Harlev E, Nevo E, Lansky E, Ofir R, Bishayee A (2012). Anticancer Potential of Aloes: Antioxidant, Antiproliferative, and Immunostimulatory Attributes. Planta Medica, 78, $843-52$.

Jassbi AR (2006). Chemistry and biological activity of secondary metabolites in Euphorbia from Iran. Phytochemistry, 67, 1977-84.

Kontos CK, Christodoulou MI, Scorilas A (2014). Apoptosis-related BCL-2-Family members: Key players in chemotherapy. Anticancer Agents Med Chem, 14, 353-74.

Kumar RA, Sridevi K, Kumar NV, Nanduri S, Rajagopal S (2004). Anticancer and immunostimulatory compounds from Andrographis paniculata. J Ethnopharmacol, 92, 291-95.

Li Z, Chen L, Rubinatein MP (2013). Cancer immunotherapy: are we there yet?. Exp Hematol Oncol, 10, 33.

Lissoni P, Messina G, Brivio F, et al (2008). Modulation of the anticancer immunity by natural agents: inhibition of $\mathrm{T}$ regulatory lymphocyte generation by arabinoxylan in patients with locally limited or metastatic solid tumors. Cancer Therapy, 6, 1011-6.

Martin-Orozco N, Muranski P, Chung Y, et al (2009). T helper 17 cells promote cytotoxic $\mathrm{T}$ cell activation in tumor immunity. Immunity, 20, 787-98.

Morioka N, Sze LL, Morton DL, Irie RF (1993). A protein fraction from aged garlic extract enhances cytotoxicity and proliferation of human lymphocytes mediated by 
interleukin-2 and concanavalin A. Cancer Immunol Immunother, 37, 316-22.

Muranaki P, Restifo NP (2013). Essential of Th17 cell commitment and plasticity. Blood, 121, 2402-14.

Nazemiyeh H, Mohajjel-Kazemi E, Zare Kh, et al (2010). Free radical scavengers from the aerial parts of Euphorbia petiolata. J Nat Med, 64, 187-90.

Nunez S, Saez JJ, Fernandez D, (2013). T helper type 17 cells contribute to anti-tumour immunity and promote the recruitment of T helper type 1 cells to the tumour. Immunol, 139, 61-71.

Mognol GP, Carneiro FR, Robbs BK, Faget DV, Viola JP (2016). Cell cycle and apoptosis regulation by NFAT transcription factors: new roles for an old player. Cell Death Dis, 21, e2199.

Orlikova B, Legrand N, Panning J, Dicato M, Diederich, M (2014). Anti-inflammatory and anticancer drugs from nature. Cancer Treat Res, 159, 123-43.

Ozbilgin S, Citoglu GS (2012). Uses of some Euphorbia species in traditional medicine and their biological activities. Turk $J$ Pharmaceut Sci, 9, 241-56.

Pahlevani AH (2007). Notes on some species of the genus Euphorbia in Iran. Rostaniha, 8, 89-103.

Punturee Kh, Wild Ch, Kasinrerk W, Vinitketkumnuen U (2005). Immunomodulatory Activities of Centella asiatica and Rhinacanthus nasutus Extracts. Asian Pac J Cancer Prev, 6, 396-400.

$\mathrm{Qu}$ Y, Easson ML, Froese J, et al (2015). Completion of the seven-step pathway from tabersonine to the anticancer drug precursor vindoline and its assembly in yeast. Proc Natl Acad Sci U S A, 12, 6224-9.

Radcliffe-Smith A (1985). Taxonomy of North American leafy spurge. Reprinted from: Leafy Spurge, Monograph series of the Weed Science Society of America. ed. Alan K. Watson, Chapter 3 (3), pp 14-25.

Romagnani S (2000). T-cell Subset (Th1 Versus Th2). Ann Allergy Asthma Immunol, 85, 9-18.

Salakou S, Kardamakis D, Tsamandas AC, et al (2007). Increased Bax/Bcl-2 ratio up-regulates caspase-3 and increases apoptosis in the thymus of patients with myasthenia gravis. In Vivo, 21, 123-32.

Siddiqui WA, Ahad A, Ahsan H (2015). The mystery of BCL2 family: Bcl-2 proteins and apoptosis: an update. Arch Toxicol, 89, 289-317.

Srancikova A, Hovathova E, Kozica K (2013). Biological effects of four frequently used medicinal plants of Lamiaceae. Neoplasma, 60, 585-97.

Tian HY, Li ZX, Li HY, et al (2013). Effects of 14 single herbs on the induction of caspase-3 in tumor cells: a brief review. Chin J Integr Med, 19, 636-40.

Wu D, Wu P, Huang Q, et al (2013). Interleukin-17: a promoter in colorectal cancer progression. Clin Dev Immunol, 43, 63-7.

Xie X, Hu Y, Xu L, et al (2015). The role of miR-125bmitochondria-caspase-3 pathway in doxorubicin resistance and therapy in human breast cancer. Tumour Biol, 36, 7185-94.

Ziaei A, Ramezani M, Wright L, et al (2011). Identification of spathulenol in Salvia mirzayanii and the immunomodulatory effects. Phytother Res, 25, 557-62.

\section{(ब) 10}

This work is licensed under a Creative Commons AttributionNon Commercial 4.0 International License. 